\title{
CRENÇAS DE LICENCIANDOS EM LETRAS SOBRE ENSINO DE INGLÊS
}

\author{
Telma Gimenez (UEL) \\ Elaine F. Mateus (UEL) \\ Denise Ismênia B.G. Ortenzi (UEL) \\ Simone Reis (UEL)
}

\section{INTRODUÇÃO}

A literatura na área de educaçáo tem sugerido que professores possuem crenças implícitas sobre ensino/ aprendizagem que guiam seu planejamento e os processos de tomada de decisóes em sala de aula (Munby, 1982; Verloop, 1989; Johnson, 1994, dentre outros). Tem sido igualmente argumentado que alunos de licenciaturas ingressam nesses programas com imagens sobre ensino/aprendizagem (Lortie, 1975, Bennett \& Carré, 1993). Esta perspectiva encontra respaldo na área de pensamento do professor, que procura compreender o ensino a partir de como pensam e agem os profissionais (Calderhead, 1987). Embora estudos em educaçáo venham trabalhando nessa perspectiva desde o início dos anos 80 , no ensino de língua estrangeira a incorporação deste referencial teórico é recente (vide Gimenez, 1995).

Entretanto, ainda têm sido poucos os trabalhos no Brasil que têm procurado estabelecer quais crenças são apresentadas por alunos dos cursos de licenciaturas, especialmente nos cursos de Letras Anglo-Portuguesas. Alguns trabalhos recentes, no entanto, têm dado relevância a crenças e suas influências nas práticas pedagógicas de professores atuantes (Damião, 1994, Felix, 1998, Reynaldi, 1998, Malatér, 1998; André, 1998) ou em fase de préserviço (Gimenez,1994 e Barcelos,1995).

A importância das crenças no processo de formação de 
professores vem sendo salientada em virtude da relaçáo entre estas e as práticas pedagógicas experienciadas pelos futuros profissionais e pela sua contribuição na elaboração do conhecimento prático pessoal. De acordo com Sadalla (1998):

As crenças representam uma matriz de pressupostos que dão sentido ao mundo, não sendo, apenas, um mero reflexo da realidade, mas sim vão sendo construidas na experiência, no percurso da interação com os demais integrantes desta realidade".(p. 32)

Nessa área, tem sido questionado o status das crenças em relação ao conhecimento e até mesmo a própria terminologia usada para se referir àquilo que os alunos-professores já trazem como "bagagem" para o curso de Letras. Algumas dessas opçóes incluem conceitos como conhecimento prático (Elbaz, 1981), entendido como conjunto de entendimentos complexo e orientado para a prática que professores empregam para moldar e direcionar o trabalho de ensino, perspectiva (Janesick, 1982), isto é, interpretaçáo reflexiva e socialmente derivada que serve de base para açōes subseqüentes, teoria implícita (Munby, 1982), relativa a estruturas coerentes que subjazem à prática pedagógica, conhecimento prático pessoal (Connelly \& Clandinin, 1984), um tipo de conhecimento que é experiencial, que faz parte e pode ser reconstruído a partir das narrativas de professores, teoria prática (Handal \& Lauvas, citado em Cole, 1990), isto é, um sistema particular, integrado, mas mutável, de conhecimento, experiência e valores relevantes para a prática pedagógica em qualquer tempo, teoria implícita (Clark, 1988), que diz respeito a agregaçōes ecléticas de proposiçōes de causa-efeito, que não são claramente articuladas mas inferidas e reconstruídas por pesquisadores, imagens (Calderhead \& Robson, 1991), que representam conhecimento sobre ensino que podem também servir de modelos para a ação. Elas geralmente incluem um componente afetivo. 
Embora cientes dessa diversidade de termos, neste estudo estamos optando pela definiçāo de "crenças", conforme Abelson (1979). De acordo com esse autor, os sistemas de crenças exibem as seguintes características:

1. Presunção existencial: os sistemas de crenças geralmente contêm proposiçóes a respeito da existência ou não existência de entidades

2. Alternatividade: as crenças tratam de "mundos" alternativos que não foram necessariamente experienciados

3. Aspectos afetivos e avaliativos: as crenças se baseiam em sentimentos, emoçóes e avaliaçóes subjetivas

4. Armazenamento episódico: as crenças derivam seu poder subjetivo, autoridade e legitimidade de episódios ou eventos específicos

5. Não-consensualidade: os sistemas de crenças consistem de proposiçóes que são reconhecidas como sendo náo consensuais

6. Desvinculação: os sistemas de crenças são tenuemente ligados e se relacionam com alguns eventos, situaçóes e sistemas de conhecimento

7. Graus de certeza: as crenças são tidas com graus variados de certeza.

Pesquisadores na área de pensamento do professor têm empregado vários métodos de investigaçáo com o objetivo de determinar crenças, indo além do comportamento observável. Conforme nos coloca Dunne (1993), "a pesquisa sobre crenças implícitas é uma área relativamente nova e difícil de ser realizada em virtude do fato de que as crenças não são observáveis e a prática não é necessariamente indício de crenças, ou 'orientaçóes teóricas' que as subjazem" (p. 73).

Tem havido um debate prolongado sobre a possibilidade de verbalização de crenças (Pajares, 1992). Os que postulam sua possibilidade de articulaçáo as consideram explícitas e presentes em nível de consciência. Os que as inferem de açóes advogam que as crenças somente podem ser reconstruídas a partir da análise de comportamentos. Ambas as posiçóes revelam a complexidade 
da relação entre comportamento/verbalização e pensamento. Estudos que procuram verificar a relação entre o 'dizer' e o 'fazer' têm apontado discrepâncias e favorecido ou o discurso ou a açáo como expressōes "verdadeiras" das crenças (e.g. Reynaldi, 1998). Entretanto, como Freeman (1993) reconhece, a linguagem tem um papel crucial no processo de formação de professores. A linguagem é reveladora de crenças quando estas são trazidas para descrever açōes, especialmente as açôes pedagógicas, quando como são feitas observaçōes de aulas de outros professores. Desta forma, as crenças funcionam como "filtros" através dos quais as práticas pedagógicas são descritas.

Neste trabalho adotamos a visão de que as crenças dos futuros professores de língua inglesa podem ser inferidas a partir de seus relatos de observaçóes de aulas de outros professores, entendimento de como se aprende a ensinar língua estrangeira é crucial no momento em que são promovidas reformulaçōes curriculares e inovaçóes no ensino de línguas estrangeiras modernas e os profissionais precisam interagir com esse corpo de conhecimentos. Os cursos de formaçáo de professores não podem ignorar as crenças que os alunos trazem e precisam encontrar formas de identificá-las e torná-las explícitas. $\mathrm{O}$ trabalho de Sadalla (1998) reforça essa visão:

" $O$ conjunto das análises realizadas permite sugerir-se que, já no periodo de formaçāo de profissionais da educação [...] sejam por eles discutidas e com eles analisadas as relaçōes entre crenças $e$ açōes docentes" (p.127).

Considerando que os alunos-professores serão profissionais que provavelmente iräo atuar na escola pública, as crenças por eles trazidas também refletem visōes que precisam ser explicitadas e posteriormente submetidas a um processo de reflexão.

A pesquisa aqui relatada, ainda em andamento, tem como objetivo identificar as crenças dos alunos-professores do curso de Letras a respeito do ensino de língua inglesa na escola pública conforme reveladas por seus relatos de observaçóes de aulas. 


\section{Análise dos relatos de aulas observadas}

Os alunos-professores de Metodologia e Prática de Ensino de Inglês observaram seis aulas de inglês em escolas públicas e elaboraram relato de observaçáo. Em seguida realizaram o planejamento de suas próprias aulas e fizeram direção de classe. Durante o ano de 1998 foi solicitado a 53 alunos-professores que escrevessem relatos de observaçáo de aulas de professores com os quais iriam estagiar. Esses relatos foram analisados primeiramente de forma exploratória, visando ao desenvolvimento de categorias. Após esta etapa, foram novamente examinados para identificaçáo das crenças manifestadas a respeito dos seguintes tópicos:

1. Papel do professor

2. Relacionamento professor/aluno, aluno/aluno

$$
2.1 \text { - Disciplina }
$$

3. Conhecimento e currículo

4. Alunos e aprendizagem

4.1 - Motivaçáo

5. Meios e práticas pedagógicas

5.1 - Materiais didáticos

5.2 - Avaliação

6. Contexto educacional

7. Contexto de estágio

8. Profissionalismo

Apresentaremos, a seguir, um breve comentário sobre os tópicos considerados mais salientes em função da análise realizada, bem como exemplos de como as crenças foram manifestadas.

1. Papel do professor

Incluíram-se nesta categoria as ocorrências de texto que diziam respeito ao desempenho do professor regente e sua responsabilidade pelo processo ensino/aprendizagem. A maior 
parte das observaçóes centraram em explicitar que competia ao professor "despertar interesse pela matéria", "diversificar as atividades da sala de aula", "buscar soluçóes para que o desânimo escolar seja superado", "tornar o aprendizado real", "falar inglês em sala", "levar textos diversificados e autênticos", "trazer atividades extras". Note-se que algumas das crenças se associam à idéia de que o professor é o grande responsável pela aprendizagem, na medida em que motiva o aluno. As descriçóes das situaçóes observadas levaram também a manifestaçóes de caráter moral, do tipo "o professor não pode se fazer de desentendido quando é perguntado sobre coisas fora do contexto da aula", "quanto à entrega de trabalho fora de prazo poderia ser solucionado com punição de diminuiçáo de nota", "o professor deve ser o sujeito que faz a interaçáo entre o saber elaborado e o que os alunos sabem".

\section{Relacionamento professor/aluno, aluno/aluno}

A indisciplina tem sido um aspecto bastante enfatizado pelos estagiários ao relatar suas experiências de estágio. Neste tópico os alunos parecem ter ido observar as aulas na expectativa de encontrar um relacionamento amigável, afetuoso, entre professor e alunos. São recorrentes afirmaçóes que se iniciam com "não há...", como por exemplo: "não há relação amistosa entre aluno/professor", "não existe o que eu esperava encontrar: diálogo, respeito entre as partes, participaçáo dos alunos em todas as atividades propostas", "não encontramos nessa relação professor/ aluno qualquer marca de cumplicidade ou companheirismo", "o professor náo acredita nos alunos e estes tampouco acreditam no professor". A interação observada na escola pública é vista geralmente de modo negativo pelos estagiários, que se distancia do que consideram ideal: "não há muita preocupaçáo por parte dos professores em saber se o aluno entendeu a matéria e os alunos também não estáo muito preocupados em saber se aprenderam ou não". 
Por outro lado, alguns alunos-professores relacionaram também a disciplina à aprendizagem, salientando a importância do professor impor respeito ou manter a distância: "acredita-se que o professor não tem muitas dificuldades em trabalhar com crianças pois mantém um considerável domínio e respeito, que ao meu ver, está relacionado ao nível de distanciamento que mantém dos alunos, pois náo proporciona nenhum tipo de aproximação, restringindo-se apenas a entrar em sala e cumprimentá-los, fazer a chamada e expor a matéria em pauta", "acredito que a distância mantida pelo professor com os alunos na sala o ajude para que estes permaneçam disciplinados, pois muitas vezes os alunos confundem 'professor legal' com bagunça".

Uma possível explicação para a indisciplina é oferecida: "para superar esses momentos que me parecem ser de sofrimento, brincam, conversam, contam piadas, etc, tudo para não prestar atenção à aula".

A forma como o professor lida com a indisciplina foi foco de comentários em que a questáo da aprendizagem foi novamente enfatizada: "o que não achei interessante foi o fato de a professora gritar muito com os alunos em certos momentos de indisciplina, acho que isso acaba por deixá-los irritados, e ainda com pouco interesse pela matéria". Alguns explicitaram sua concepção de como o problema poderia ser resolvido: "penso que para lidar com este tipo de aluno náo basta usar a coerência, porque o aluno deverá sentir que a escola não é sua casa, onde ele talvez imponha seus limites e também deverá entender que a escola não espera dele apenas um comportamento moral, mas também social e político".

O relacionamento aluno/aluno foi observado pelos estagiários principalmente no aspecto de amizade: "os alunos não são muito amigáveis uns com os outros, pois quando um erra a pronúncia de uma palavra, ou náo sabem responder uma pergunta do professor, os outros gozam, fazem piadinhas, rotulam o colega".

SIGNUM: Est. Ling., Londrina, n.3, p.125-139, set. 2000 


\section{Conhecimento e currículo}

A qualidade da língua inglesa que poderia ser apresentada aos alunos foi alvo de observaçōes dos estagiários, salientando aspectos da contextualização e da "realidade" dos alunos. Exemplos de crenças a este respeito: "náo é despertada nenhuma ligaçáo da matéria aplicada com o cotidiano dos alunos, como se a aula fosse um mundo fora de suas vidas", "o professor ministra as aulas de maneira descontextualizada da realidade de seus alunos, o que não produz para eles nenhum significado para aprender", "poderiam falar de suas vidas, o que pensam sobre a escola, e assim estimular e fortalecer suas experiências com a língua inglesa".

A gramática, freqüentemente ensinada no contexto observado, é considerada importante para a aprendizagem, porém limitadora da criatividade do aluno.

Ainda sob esta categoria os alunos-professores reforçaram o fato de que a língua estrangeira tem um papel secundário na distribuição curricular: "na escola o inglês não reprova, ou seja, náo tem o mesmo status de outras disciplinas".

Alguns alunos consideram o conhecimento da língua estrangeira necessário para a vida futura dos alunos no mundo do trabalho: "os alunos devem ver na língua estrangeira uma maneira de crescerem profissionalmente e interagirem com a sociedade"; "o ensino de língua inglesa deve servir como meio de comunicação/interação entre os povos, pois é através da língua que o indivíduo consegue estabelecer relaçóes com ele".

\section{Alunos e aprendizagem}

Tem sido constante entre futuros professores de inglês a crença de que a motivaçáo é essencial para a aprendizagem, conforme apontado em algumas das categorias já apresentadas. Os fatores associados à aprendizagem identificados pelos informantes se configuram em afirmaçōes como: "os alunos 
precisam de atividades que estimulem a criatividade para a aula não ficar táo cansativa", "acreditamos ser o componente afetivo de grande importância para a aprendizagem", "o que muitas vezes vem a desmotivar o aluno é o fato de eles não encontrarem objetivos concretos naquilo que está sendo ensinado", "eles não sabem usar o que é ensinado por isso não sentem-se motivados com a matéria e não há muito êxito durante a aula”.

A falta de êxito nas aulas é vista como causadora da desmotivação: "aqueles que não participavam da aula tinham vergonha de falar e errar, ou queriam entender tudo sobre a aula, não conseguiam e, assim, se desmotivavam".

Para motivar os alunos, de acordo com esses informantes, seria necessário "adaptação às lições do livro", "diversidade das atividades", maior uso da língua estrangeira na própria sala de aula, e outras sugestôes que serão detalhadas no item a seguir.

\section{Meios e práticas pedagógicas}

Considerando-se que as aulas observadas ficavam aquém do esperado pelos estagiários, estes mencionaram várias sugestóes de como superar as dificuldades relatadas. Exemplos dessas atividades são: "adaptação das liçóes do livro", "contextualização dos diálogos", "dar maior importância ao trabalho de exploração do contexto", "levar para sala textos diversificados", "levar música à sala", enriquecer "mais as aulas com recursos como utilização de vídeo, exercícios de listening etc.", levar à reflexão, propor a produção oral por parte dos alunos, fazer discussóes a respeito do conteúdo dos textos e leituras para interpretação.

Referências ao livro didático colocam crenças de que este deve servir apenas como um apoio: "o que cabe ressaltar e analisar é a supremacia absoluta do livro didático que torna a aula enfadonha, monótona e pouco atraente"; "seria útil apenas como um roteiro, mas não para tanto uso assim"; "o livro didático deveria servir apenas como um gancho para as aulas".

Outras crenças apresentam total rejeição ao livro didático

SIGNUM: Est. Ling., Londrina, n.3, p.125-139, set. 2000 
e percepção negativa da relação professor/livro didático: "deveria ser mudado tudo: abolido o livro didático"; "o livro era uma prisão ou mesmo uma dependência da profissional". Para outros informantes, o livro didático inibe a aprendizagem, tornando-a "cansativa e gerando dispersão".

Por outro lado, o uso do livro didático é visto como uma prática cômoda diante das condiçóes de trabalho do professor: "livro didático são os olhos da professora. Poupa esforço"; "tornase cômodo pois não é preciso que as aulas tenham uma preparaçáo antes de acontecer".

Ainda com a perspectiva de que a escola deveria estar atuando de modo diferente do observado pelos estagiários, a avaliação é vista como inadequada, em comentários como: "avaliação deveria ser também pela participaçáo", "avaliaçáo deve avaliar o aluno como um todo", "o professor só as faz por mera formalidade, por exigência do corpo escolar", "a avaliação oral tem que ser feita durante todas as aulas". Foi também observado pelos estagiários que há uma certa pressão para que o aluno não reprove e isto o leva a uma atitude de descaso: "[...] faz com que este, que não é nada bobo, deixe de estudar e passe a tumultuar a aula, ciente, é claro, que no final tudo acabaria em pizza e ele, sem maiores problemas, passaria para a próxima série".

As condiçóes de trabalho do professor inserem-se em uma categoria mais abrangente de crenças que engloba questóes sobre o contexto educacional. É para esta categoria que agora direcionamos a análise.

\section{Contexto Educacional}

As crenças relativas ao Contexto Educacional revelam aspectos negativos para justificar a dificuldade na aprendizagem do aluno e no trabalho de ensinar do professor: "quando o educando vai ser avaliado, as condiçóes emocionais como ansiedade e nervosismo, além de outros problemas como a má alimentação do aluno, serão fatores que interferirão 
negativamente na resolução da prova"; "o nível social dessa turma é inferior em relação aos alunos da quinta série, a maioria das mães são empregadas domésticas, zeladoras da escola, pessoas simples que por algum motivo náo continuaram seus estudos, me recordo apenas de uma criança cujo pai tem terceiro grau completo. Cheguei a pensar que por esses motivos, por ver a situação de casa, as dificuldades, alguns prevêem que não continuarão os estudos $\mathrm{e}$ acabam perdendo o interesse"; "o excessivo número de alunos já é um fator que prejudica muito o trabalho em qualquer disciplina"; "em uma aula de cinqüenta minutos não é possível dar muita coisa"; "professor que não é bem remunerado náo tem condiçóes de trazer materiais paralelos ao livro didático, pois para providenciálos gasta-se muito e a maioria das escolas não tem como fornecer esses recursos ao professor".

Quando os alunos-professores fazem menção ao ensino em escola de línguas parecem crer que aquela é uma situação privilegiada pois oferece "diversos recursos", os alunos estão ali porque querem, gostam e participam mais do que na aula da escola pública. Para alguns, para aprender é preciso "fazer academia".

Ao tentarem identificar o conjunto de fatores que interferem no ensino/aprendizagem da língua inglesa, os alunosprofessores englobam os pais dos alunos, e seu nível sócioeconômico-cultural bem como seu entendimento sobre a importância de adotar livro didático, a comunidade civil, os representantes políticos, os traços da "sociedade contemporânea", vista como tecnológica e consumista, e a própria implementação do currículo oficial.

\section{Contexto de estágio}

Mesmo sem serem solicitados a comentar sobre o estágio, alguns informantes fizeram observaçóes com relaçáo à experiência vivida: "sempre fica aquela sensação de que, porque estamos estagiando, os alunos não nos respeitaráo tanto", "a falta de interação distancia-se radicalmente dos conceitos aprendidos no 
curso de Letras e dos conceitos pessoais do ideal de aula", "é ainda nesse período que começamos a refletir sobre nosso papel de educadores, quais atitudes vou tomar, como vou ensinar, e vários outros questionamentos, que talvez nem todos sejam respondidos no período de regência", "vi que dar aula não é um pesadelo. Meu maior medo era enfrentar uma sala, mas gostei muito. Com traquejo pode-se chegar onde se quer".

A prática como principal formador do professor aparece em um relato: "[...] muitas dúvidas que só serão esclarecidas quando estiver exercendo a profissão". A expectativa de que a prática do próprio estagiário será diferente da observada se revela em alguns dos informantes: "tentarei, nas aulas de estágio, despertá-los e motivá-los para as aulas, mostrarei qual a importância dessa matéria, conscientizarei do porquê estudar uma língua estrangeira nos dias de hoje", "tentei pelo menos motivá-los diferentemente da professora regente, diversificando as atividades de sala de aula".

\section{Profissionalismo}

O julgamento dos professores observados, embora não encorajado necessariamente pela tarefa de redação dos relatórios, pode ser identificado a partir dos comentários a respeito da prática "real" versus a "ideal". Professores desmotivados, acomodados, sobrecarregados são vistos como entraves à aprendizagem e algumas propostas são colocadas: "escola e governo deveriam atuar juntos para motivar o professor para que se atualize", "[....] cansado com a enorme quantidade de turmas que acumula para que tenha um salário decente, ele não dispóe de nenhum tipo de esforço, pois acaba achando isso desnecessário já que surge aquele velho tabu em que se diz que alunos da escola pública não aprendem nada, quanto mais inglês", "eles, os professores, também desacreditam do ensino das escolas públicas e não têm motivaçáo para trabalhar, mas a partir do momento em que o professor escolheu exercer esta profissão, ele deve de alguma maneira, seja com recursos ou sem, tornar suas aulas interessantes e mostrar 
"paixão" por aquilo que faz", "deveria colocar o melhor de si em seu trabalho e encarar todas as barreiras, pois afinal foi ele próprio que escolheu sua profissão", "acredito que falte um pouco de apoio e incentivo do governo, no sentido de remunerar melhor os professores para que os mesmos náo precisem 'pegar' tantas turmas, para ter um salário mais ou menos digno".

\section{Consideraçóes finais:}

A análise preliminar dos dados aqui apresentada delineia algumas tendências apresentadas pelos estagiários ao relatar aulas observadas na escola pública. A preocupação principal é, naturalmente, com o processo de ensino/aprendizagem e os fatores potencialmente influentes: relacionamento professor/aluno, material didático, motivação, disciplina, práticas pedagógicas $\mathrm{e}$ contexto educacional. Aspectos do próprio estágio e do grau de profissionalismo do professor observado também fizeram parte de alguns relatórios.

O que parece evidente é um quadro bastante negativo do ensino no contexto observado, em que a maior responsabilidade é atribuída ao professor. Nesse sentido, a própria prática é idealizada como aquela que vai ser diferenciada e, portanto, capaz de reverter a situação encontrada.

É interessante observar que esses relatos foram escritos ainda na fase inicial da prática de estágio e sem um direcionamento explícito no sentido de guiar a descrição. No entanto, como pudemos demonstrar, as crenças sobre ensino/ aprendizagem já se apresentam constituídas mesmo antes de sua experiência prática na condução de aulas. Este resultado corrobora estudos anteriores que tratam do conhecimento trazido pelos futuros professores para os cursos de formação.

Apesar de terem sido raros os relatórios meramente descritivos feito pelos alunos, o tipo de tarefa que lhes foi proposta resultou em rica fonte de dados e, portanto, eficiente instrumento de pesquisa. Considerando que este trabalho ainda terá 
continuidade, no sentido de analisar as crenças sob a perspectiva da linguagem, esperamos poder contribuir do ponto de vista metodológico para eliciação de crenças na fase inicial do processo formal de educação de professores. Embora de forma incipiente pudemos observar marcas de negaçáo (como por exemplo, "náo há", "não existe"), bem como ausências ("falta de...") que evidenciam expectativas não correspondidas. Assim, os graus de certeza das crenças poderão ainda ser detectados através dessas análises complementares.

Trabalhos desta natureza podem ser relevantes para a formaçáo de professores de inglês na medida em que a identificação de crenças seja ponto de partida para o programa definir objetivos e açóes pedagógicas que possam levar o futuro professor a reconhecê-las e superá-las, se assim for considerado desejável. Nesse sentido, desenvolver instrumentos que possam auxiliar nesse processo de identificação é parte de uma filosofia de programa comprometido com a reflexáo como paradigma de desenvolvimento profissional.

\section{REFERÊNCIAS BIBLIOGRÁFICAS}

ABELSON, R. (1979) Differences between belief systems and knowledge systems. Cognitive Science 3, p. 355-366.

ANDRÉ, M. (1998) A construção do conhecimento do futuro professor de inglês como língua estrangeira por meio da conscientização de suas crenças educacionais. Comunicação durante o V CBLA, Porto Alegre.

BARCELOS, A.M.F. (1995) A cultura de aprender língua estrangeira (inglês) de alunos formandos de Letras. Diss. Mestr. , Campinas: UNICAMP.

BENNETT, N. \& CARRÉ, C. (orgs) (1993) Learning to teach.New York: Routledge.

CALDERHEAD, J. (1987) Exploring Teachers'Thinking. Londres: Cassell.

DAMIÃO, S. M. (1994) Crenças de professores de Inglês em escolas de idiomas - um estudo comparativo. Diss. Mestr. , São Paulo: PUCSP. 
DUNNE, E. (1993) General beliefs about teaching and learning. In: N. Bennett \& C. Carré (orgs) Learning to teach.New York: Routledge, p. 73-87.

FELIX, A.(1998) A influência das crenças adquiridas durante a aprendizagem no fazer do professor em sala de aula. Comunicação durante o VCBLA. Porto Alegre.

FREEMAN, D. (1993) 'To take them at their word': the use of language data in the study of teachers'knowledge. Trabalho apresentado durante a Conference of the International Study Association on Teacher Thinking. Suécia, Agosto.

GIMENEZ, T. (1994) Learners becoming teachers: an exploratory study of beliefs held by prospective and practising EFL teachers in Brazil. Tese de Doutoramento. Lancaster, UK: Lancaster University.

GIMENEZ, T.(1995) O ensino de línguas estrangeiras na perspectiva do professor. Semina 16(3), p. 485-490.

JOHNSON, K. E. (1994) The emerging beliefs and instructional practices of preservice ESL teachers. Teaching and Teacher Education 10 (4), p. 439-452.

LORTIE, D. (1975) Schoolteacher: a sociological study. Chicago: University of Chicago Press.

MALATÉR, L. S. (1998) Teacher's beliefs on foreign language acquisition: a case study on classroom behaviors. Diss. Mestr. Florianópolis: UFSC.

MUNBY, H (1982) The place of teachers'beliefs in research on teacher thinking and decision-making and an alternative methodology. Instructional Science 11, p. 201-225.

PAJARES, M. F. (1992) Teachers'beliefs and educational research: cleaning up a messy construct. Review of Educational Research 62 (3), p. 307-332.

REYNALDI, M.A.(1998) A cultura de ensinar língua materna e língua estrangeira em um contexto brasileiro. Diss. Mestr. Campinas: UNICAMP.

SADALLA, A.M. F.A. (1998) Com a palavra, a professora: suas crenças, suas açóes. Campinas, SP: Editora Alínea.

VERLOOP, N. (1989) Interactive cognitions of student teachers: an intervention study. Arhem: National Institute for Educational Measurements.

SIGNUM: Est. Ling., Londrina, n.3, p.125-139, set. 2000 